\title{
O IDEALISMO DE HEGEL COMO INSPIRAÇÃO PRIMEIRA DA COMPOSIÇÃO DA PERSPECTIVA ONTOEPISTEMOLÓGICA MATERIAL-DIALÉTICA DE MARX
}

\author{
Antonio Dias ${ }^{1}$
}

\begin{abstract}
Resumo:
Assumimos a tese de que o pensamento de Marx é bem qualificado quando nomeado de perspectiva ontoepistemológica material-dialética. Com base nisso, o objetivo deste texto é argumentar que essa perspectiva é substancialmente forjada pelas críticas de Marx à filosofia dialética idealista de Hegel, críticas que não implicam excluir o pensar, as ideias, as contradições etc., de participarem como conteúdo do princípio Materialdialético. Isto demonstrado significa que o pensamento filosófico hegeliano, ainda que por um caminho crítico negativo, deve ser admitido como inspiração da Filosofia Material-dialética marxiana.
\end{abstract}

Palavras-chave: Marx. Hegel. Perspectiva ontoepistemológica. Material-dialético.

\section{THE IDEALISM OF HEGEL AS THE FIRST INSPIRATION FOR THE COMPOSITION OF THE MATERIAL-DIALETIC ONTOEPISTEMOLOGICAL'S PERSPECTIVE OF MARX}

\begin{abstract}
:
We assume the thesis that Marx's thought is well qualified when named material-dialectic ontoepistemological perspective. On the basis of this, the aim of this text is to argue that this perspective is substantially forged by Marx's criticisms of Hegel's idealist dialectical philosophy, criticism that do not imply excluding the ideias, thinking, contradictions, etc., from participating as content of the material principle Material-dialectic. This demonstrates means that the hegelian philosophical thought, though by a negative critical path, must be admitted as the inspiration of marxian Material-dialectical Philosophy.
\end{abstract}

Keywords: Marx. Hegel. Ontoepistemological perspective. Material-dialectic.

Marx extraiu alguns fundamentos do seu pensamento Material-dialético da Filosofia idealista do filósofo George W. F. Hegel. Ao buscar bases teóricas e critérios iniciais para compor uma perspectiva analítico-crítica, por meio da qual pudesse compreender a realidade - em seu estatuto ontoepistemológico ${ }^{2}$, suas conexões e determinações, enfim, a lógica do movimento (de engendramento, desenvolvimento, conservação e transformação) do real, - Marx recorreu à dialética idealista que Hegel expôs na Fenomenologia do Espírito e

1 Antonio Dias é Doutor em Educação: Filosofia da Educação (UFPel), com Doutorado Sanduiche na Universidade de Lisboa; Mestre em Filosofia (UFC). Professor na Universidade Estadual do Piauí (UESPI), Teresina-Piauí-Brasil. $\quad$ Lattes: $\quad$ http://lattes.cnpq.br/0523200571305788. E-mail: prof.antoniofldias@gmail.com

"Entendo que há, no processo de fundamentação no 'Materialismo' de Marx, o enlaçamento do ontológico com o epistemológico; e este é o motivo de nomear a perspectiva marxiana de 'ontoepistemológica'. A Ontologia versa sobre questões do Ser; a Epistemologia trata da natureza, possibilidades e meios do conhecimento. Marx foca a realidade como totalidade; ele não separa ser e pensar, existência e consciência. Por isso, sua perspectiva é ontoepistemológica" (DIAS, 2016). 
na Ciência da Lógica, ora para afirmá-la, ora para negá-la. O próprio Marx revela seu itinerário.

Em um relato autobiográfico de 1859, escrito para prefaciar a obra Para a Crítica da Economia Política, Marx lembrou o contexto em que iniciou sua trajetória na direção de formatar o "novo materialismo", o Materialismo-dialético ${ }^{3}$ — que, doravante, seria a base teórico-metodológica de toda sua Filosofia —, escrevendo assim: "no ano de 1842-43, como redator da Rheinische Zeitung ${ }^{4}$, vi-me pela primeira vez perante a dificuldade de ter também de dizer alguma coisa sobre o que se designa por interesses materiais” (MARX, 1982, p. 529). Em seguida, Marx formula que os conteúdos desses "interesses materiais" são "os debates [...] sobre o roubo de lenha e parcelamento da propriedade fundiária [...], a situação dos camponeses do [vale do rio] Mosela, as discussões sobre livre-cambismo e tarifas alfandegárias protecionistas" (MARX, 1982, p. 530).

Notem, antes de algo mais, que os "interesses materiais" referidos por Marx dizem respeito ao papel, atuante e/ou omisso, do Estado enquanto, em termos jurídicos (burguês) e filosóficos (hegeliano), esfera promotora dos interesses gerais e campo da concretização da liberdade de todos. São “interesses" que se prestam a determinada organicidade e funcionamento (lógica) das instituições e relações (econômicas, políticas, educacionais etc.).

Para debater sobre os "interesses materiais", Marx busca por um aporte teórico. Neste sentido, escolhe dialogar com Hegel ${ }^{5}$. Diz Marx:

\begin{abstract}
O primeiro trabalho, empreendido para resolver as dúvidas que me assaltavam, foi uma revisão crítica da filosofia do direito de Hegel, um trabalho cuja introdução ${ }^{6}$ apareceu nos Deutsch-Französische Jahrbücher ${ }^{7}$, publicados em Paris em 1844. A minha investigação desembocou no resultado de que relações jurídicas, tal como formas de Estado, não podem ser compreendidas a partir de si mesmas nem a partir do chamado desenvolvimento geral do espírito humano, mas enraízam-se sim, nas relações materiais da vida, cuja totalidade Hegel [...] resume sob o nome de "sociedade civil" (MARX, 1982, p. 530).
\end{abstract}

3 Engels relata que "a consciência da total inversão em que o idealismo alemão incorrera" foi o que induziu ele e Marx a se abrigarem sob "o materialismo"; mas não qualquer materialismo. Por exemplo, não o "materialismo exclusivamente mecânico do século XVIII. [...]. [Mas sob o] materialismo moderno [que] é substancialmente dialético" (ENGELS, 1979, p. 23). E, como tal, é a superação, simultaneamente, do materialismo tosco (velho, mecanicista) e do idealismo (hegeliano etc.).

4 Gazeta Renana.

5 Marx "revisou criticamente" a obra Princípios da Filosofia do Direito, de Hegel. O resultado desse estudo originou a Crítica da Filosofia do Direito de Hegel, cujos conteúdos que se têm publicado são os parágrafos 261 a 313, da $3^{\text {a }}$ Seção, da $3^{\text {a }}$ Parte, referentes ao "Estado", na obra de Hegel.

6 Trata-se do artigo Crítica da Filosofia do Direito de Hegel - Introdução.

7 Anais Franco-Alemães.

\begin{tabular}{|l|l|l|l|l|}
\hline Q Povista Dialectus & Ano 5 & n. 12 & Janeiro - Julho 2018 & p. 303-313 \\
\hline
\end{tabular}


A "conclusão" a que chegou Marx é uma afirmação do Material como fundamento ontológico ${ }^{8}$ do real. Notamos, todavia, que, considerando os termos da supracitada citação, bem como aquilo que são os conteúdos dos "interesses materiais", que, para Marx, o aceite do Material como princípio ontológico não confere à materialidade biofísico-química o status de exclusivo conteúdo do princípio Material-dialético determinante do real.

A sentença afirmativa do Material como arché não suprime o movimento, a contradição, as ideias (enquanto expressões do pensamento sobre o real: o Eu, o Outro e o Mundo), da condição de conteúdo do processo de determinação do real. Quando Marx diz que as "relações" constitutivas do real ("Estado", "relações jurídicas" etc.) "têm raízes nas relações materiais da vida, cuja totalidade Hegel" nomeou de "sociedade civil", dá-nos uma ocasião para percebermos o sentido do "material" que ele admite. Diferente de Hegel, Marx concebe a "sociedade civil" como um "concretum", e não um "abstractum". O fundamento ontológico do "material" marxiano, portanto, emana de situações e relações cujos sujeitos são os homens vivendo em sociedade; e esta, decerto, não existe sem o ato de pensar, sem as ideias, sem as contradições e certa consciência do Eu, do Outro e do Mundo.

Após essas conclusões no plano ontológico, Marx move-se para o campo epistemológico de onde garante que aquelas conclusões basearam a criação de sua perspectiva de investigação e exposição sobre o real.

O resultado geral a que cheguei e que, uma vez obtido, serviu-me de fio condutor aos meus estudos, pode ser formulado sucintamente assim: [...]. O modo de produção da vida material é que condiciona o processo da vida social, política e espiritual. Não é a consciência dos homens que determina o seu ser, mas, inversamente, o seu ser social que determina a sua consciência (MARX, 1982, p. 530-531, grifos meus).

Atenção: na passagem supradita, Marx, do campo epistemológico, indica o que "lhe serviu de fio condutor" dos "seus estudos"; que seu ponto de partida nas investigações sobre a realidade não é o que está, a priori, na consciência, como resultante do pensar. Contudo, apesar da ressalva imperativa — de que não se deve começar pela consciência Marx não advoga que o pensar e seus produtos (ideias, consciência etc.) devam ser ignorados

8 Adoto o conceito de Ontologia proposto por Barata-Moura para quem "a Ontologia é o campo onde se inscrevem todos os respondimentos" - não importando o conteúdo das respostas — "à [clássica] pergunta dos gregos [antigos], encontrada em Platão, em Aristóteles e também em Hegel e muitos outros: — 'que é aquilo que é?'.”' (BARATA-MOURA, 2014, p. 238).

\begin{tabular}{|l|l|l|l|l|}
\hline Qevista Dialectus & Ano 5 & n. 12 & Janeiro - Julho 2018 & p. 303-313 \\
\hline
\end{tabular}


no processo para conhecer. E porque Marx está se manifestando do plano epistêmico, é indevido dizer que ele concluiu que as ideias, a consciência etc., não participam do processo Material-dialético de formação do homem como ser humano-social.

Portanto, Marx, seja do campo ontológico, seja da esfera epistemológica, entende que os homens são seres que, para atuarem de maneira social, econômica, política etc., não podem prescindir do pensar, das ideias, da consciência. O trabalho, que Marx considera como atividade constituinte da condição humano-social, assim o é na medida em que é antecipado no pensamento que se exterioriza como ideias, teorias etc. Em suma: a argumentação de Marx evidencia a articulação entre os campos ôntico e epistêmico. Por esse caminho, Marx faz aparecer as bases da sua Perspectiva ontoepistemológica Material-dialética.

Do contato com a Filosofia hegeliana, com o intuito de "resolver as dúvidas que lhe assaltavam", pode-se inferir que Marx chegou às seguintes conclusões: 1) "o material” é o determinante do real; 2) essa condição, porém, não implica abolir o papel (re)ativo do pensar, das ideias, da consciência. Pode-se dizer, também, que Marx, no itinerário para compor sua perspectiva ontoepistemológica seguiu com e contra Hegel. Apesar de os discursos mais costumeiros serem os que visam demarcar diferenças entre a dialética de Marx e a de Hegel, para divorciá-las, o próprio Marx afirma que o arquétipo da sua dialética é a dialética de Hegel. ${ }^{9}$ Isto impõe que façamos mais contatos com conceitos da lógica dialética hegeliana para melhor percebermos como essa dialética inspirou a perspectiva ontoepistemológica Material-dialética de Marx.

Conforme Hegel, "a Ideia”, via mediação das contradições, possui o pleno poder de determinação da totalidade do real. Neste sentido, afirma que: "a lógica [dialética] mostra a elevação da ideia para o grau em que ela se torna criadora da natureza" (HEGEL, 1970, p.

9 "Marx baseou-se explicitamente na estrutura reflexiva da lógica dialética de Hegel, substituindo, entretanto, a lógica do conceito por aquela de um processo material" (FLICKINGER, 1986, p. 137). Por diversas vezes Marx afirmou seu débito para com a dialética de Hegel. Uma destas foi numa carta que ele enviou a Engels em Janeiro de 1858. Na ocasião, Marx (1973, p. 91) escreveu: "No método de trabalhar, prestou-me um grande serviço que eu [...] tivesse voltado a folhear a 'Lógica' de Hegel. Se alguma vez eu voltar a ter tempo para tais trabalhos, teria grande prazer de, em 2 ou 3 folhas de impressão, tonar acessível ao comum entendimento dos seres humanos o racional no método [dialético] que Hegel descobriu, mas que, simultaneamente, tratou de mistificar".

Não obstante Marx admitir sua dívida para com a dialética de Hegel, intérpretes seus, como Louis Althusser e György Lukács, negam isso. Este último, por exemplo, entende que a herança hegeliana não é tão significativa para a construção do pensamento marxiano. Para Lukács (2010, p. 157), "a famosa negação da negação" "praticamente nem aparece" em Marx; e, n'O Capital, essa expressão tem um caráter "estilisticamente decorativo". Para Lukács, ao contrário das conclusões a que chegou Engels, no seu AntiDhuring e na Dialética da Natureza, a negação da negação tem um valor essencial, mas não para o método de Marx; a negação da negação "desempenha um papel [importante somente] na estrutura dialética do sistema hegeliano" (LUKÁCS, 2010, p. 158).

\begin{tabular}{|l|l|l|l|l|}
\hline Q Rovista Dialectus & Ano 5 & n. 12 & Janeiro - Julho 2018 & p. 303-313 \\
\hline
\end{tabular}


524), da realidade em geral; "somente a ideia absoluta é ser, vida imperecível, verdade que conhece a si mesma, e é toda a verdade" (HEGEL, 1970, p. 725). Por essa razão, "a determinidade da ideia e todo o curso desta determinidade constitui o objeto da ciência da lógica" (HEGEL, 1970, p. 726).

Consoante o pensamento de Hegel, "a Ideia" aciona o movimento gerador do real, que é constituído de espírito e matéria. "A Ideia" não é a exclusão do "material”; ela, aliás, precisa plasmar-se no mundo material objetivo, habitar a Natureza, o mundo físico da vida dos homens. Somente assim "a Ideia" deixará de ser pensamento puro (lógico) e desencadeará seu ciclo (de vida) dialético, pelo qual se configura para mostrar-se como "razão" (causa) fundante da totalidade da realidade e, enfim, fechar o seu ciclo retornando a si, agora como "espírito absoluto".

Esse processo, em que a "ideia" sai de si para exteriorizar-se no mundo e, depois, retorna para si, realiza-se pela mediação das contradições: porque "todas as coisas são em si mesmas [em essência] contradição" (HEGEL, 1970, p. 386). E acrescenta: "a contradição é a raiz de todo o movimento e vitalidade; somente na medida em que uma coisa tem em si uma contradição é que ela se move, possui impulso e atividade"10 (HEGEL, 2011, p. 165). O fato de cada coisa/relação conter a contradição (o não-Ser) em sua essência (no seu Ser) caracteriza o movimento de constituição da realidade como processo dialético.

\begin{abstract}
O raciocínio que formula a falsa pressuposição da separação absoluta entre o ser e o não ser, e permanece nesta separação, não deve ser chamado de dialético, e sim de sofistaria. Pois a sofistaria significa um raciocínio procedente de uma pressuposição destituída de fundamento, que se deixa valer sem crítica e irrefletidamente; em vez disso, chamamos de dialética o movimento racional superior, no qual tais elementos [ser e não ser], que aparecem absolutamente separados, por meio de si mesmos, por meio do que eles são, passam de um ao outro; e, assim, a pressuposição [da separação] se supera. É da imanente natureza dialética do ser e do nada [Não-Ser] que eles mesmos mostrem sua unidade, o devir, como a sua verdade (HEGEL, 1970, p. 95-96).
\end{abstract}

O fato de, no processo dialético, um ser "passar ao outro", negando-se, não desemboca no "nada". 11 Se a negação e/ou "superação" de algo gerar "o nada", isto cessa o

10 "Todavia, é um dos pré-conceitos fundamentais da lógica [formal, clássica,] até aqui aceita e da representação habitual crer que a contradição não é uma determinação tão essencial e imanente como a identidade" (HEGEL, 1970, p. 386).

11 "O que se supera [dialeticamente], não se torna, por isso, nada. [...]; algo superado é algo mediado [que transitou de/para] [...]; ele [o superado] tem, portanto, ainda em si a determinidade da qual procede. Superar [Aufheben] tem na língua [alemã] o sentido duplo, pois significa tanto conservar, manter, quanto, simultaneamente, deixar de ser, terminar algo" (HEGEL, 2011, p. 98).

\begin{tabular}{|l|l|l|l|l|}
\hline Revista Dialectus & Ano 5 & n. 12 & Janeiro - Julho 2018 & p. 303-313 \\
\hline
\end{tabular}


movimento, e não mais haverá circunstâncias/condições para o "devir", o porvir. Por essa razão,

\begin{abstract}
a única maneira de alcançar o progresso científico [...] é o reconhecimento da proposição lógica que afirma que o negativo [o Não-Ser] é [também] o momento positivo [o Ser], ou que o que se contradiz não é resolvido em um zero, no nada abstrato, mas apenas essencialmente na negação de seu conteúdo em particular; ou seja, que tal negação não é toda negação, e sim a negação de determinada coisa, que se resolve, e por isso é uma negação determinada [específica, não absoluta] (HEGEL, 1970, p. 50).
\end{abstract}

Seguindo esse raciocínio, Hegel responde à questão "qual deve ser o começo da ciência?" (HEGEL, 1970, p. 63) nos seguintes termos: "quando um concreto [o Material] é tornado ponto de partida, falta a prova necessária para se estabelecer a ligação entre as determinações contidas no concreto" (HEGEL, 1970, p. 72). Em face desse preceito idealista de Hegel, Marx assume uma posição antípoda que pode ser expressa assim: quando "a Ideia" é feita "ponto de partida", "falta a prova necessária para estabelecer" nexos "entre as determinações contidas" na "Ideia". Desta forma, Marx distancia-se de Hegel e avança na direção de estabelecer as primeiras bases do seu Materialismo: o materialismo onde "o Material" é dialeticamente conectado.

De acordo com Marx, a tentativa de transmudar do mundo das ideias diretamente para o mundo material só tem sentido no interior de uma filosofia especulativa como é o caso da lógica de Hegel. Não sem ironia, mas sem desprezo, Marx assevera que a lógica de Hegel é a escrita "biográfica da Substância abstrata, da Ideia" (MARX, 2010, p. 58). E eis que, neste ponto, jaz a mais notável divergência entre a dialética de Marx e a de Hegel, qual seja: o fato de que, para Marx, o fator determinante do real é o Material-dialético, enquanto que Hegel pensa ser "a Ideia".

Apesar dessas críticas, é preciso dizer que Marx, talvez, não seguiria o caminho materialista caso não tivesse encontrado com a filosofia (neo)hegeliana. Em que pese as discrepâncias, Marx assume, ao abrigo de um viés materialista, a validade e o sentido das categorias "totalidade", "contradição", "determinação" presentes e decisivas na dialética hegeliana. Adota, pois, a dialética idealista de Hegel como arquétipo ou protótipo da sua dialética materialista por considerar que "a mistificação que a dialética sofre às mãos de Hegel de modo nenhum impede que tenha sido ele a expor, pela primeira vez, de um modo abrangente e consciente as suas [da dialética] formas de movimento universal” (MARX, 1990, p. 22).

\begin{tabular}{|l|l|l|l|l|}
\hline Gevista Dialectus & Ano 5 & n. 12 & Janeiro - Julho 2018 & p. 303-313 \\
\hline
\end{tabular}


Dito isto, proponho retornarmos à Crítica da Filosofia do Direito de Hegel. É nesse escrito que Marx faz contundentes afirmações que marcam seu distanciamento (da posição política e) da dialética idealista de Hegel, ao mesmo tempo em que forja os primeiros enunciados da sua dialética materialista. Por exemplo, é na Crítica que Marx censura a tese de "Hegel de que o verdadeiro princípio material é [...] a Ideia absoluta, que não guarda em si nenhum momento passivo, material” (MARX, 2010, p. 130). Ora, Marx discorda veementemente da tese de que, na construção da realidade, "o material" não tenha sequer um papel "passivo"; e que todo o poder ativo constituinte do real pertença unicamente à "Ideia". Ao pensar desse modo, diz Marx, Hegel "transforma em sujeitos [...] as categorias lógicas abstratas" (MARX, 2010, p. 38).

Vamos considerar um exemplo desta antropologização e autonomização das ideias/categorias "lógico abstratas". Hegel concebe que "a finalidade e os poderes do Estado" são formas lógicas da realização da "ideia de Estado". Para Marx, tal gesto é uma maneira de "mistificar" o legítimo fundamento dos fins e da autoridade "dos poderes do Estado". Ainda conforme Marx, Hegel comete a seguinte inversão: "a condição [a sociedade civil] torna-se o condicionado, o determinante (das Bestimmende) torna-se o determinado (das Bestimmte), o produtor [o povo] é posto como produto de seu produto [do Estado]" (MARX, 2010, p. 3031). A mistificação aí contida consiste na contraversão de papéis entre o Estado e a sociedade civil. Para Marx, essa proposição hegeliana é, em síntese, uma deformação do real. ${ }^{12}$

A dialética de Hegel é a dialeticidade ou movimento da "Ideia". Marx (2010, p. 108) avalia que, desse jeito, Hegel "compreende e reconhece, por toda parte, as determinações (Bestimmungen) do Conceito lógico, mas não apreende a lógica peculiar do objeto específico"; que Hegel quer fazer aparecer a "Ideia" como matriz da realidade ("a lógica da coisa") desconhecendo as causas da logicidade do real (“a coisa da lógica”) (MARX, 2010, p. 38-39). A dialética de Hegel funda e explica a realidade pela "Ideia", a partir da subjetividade: da cabeça do Ser-que-pensa.

Ao contestar essas teses de Hegel, parece que Marx se dirige para referendar outra tese: a de que "o Material" anula qualquer participação das ideias como base fundante e

12 "O conteúdo concreto, a real determinação (Bestimmung), aparece como formal; a forma inteiramente abstrata de determinação aparece como o conteúdo concreto. A essência das determinações (Bestimmungen) do Estado não consiste em que possam ser consideradas como determinações do Estado, mas sim como determinações (Bestimmungen) lógico-metafísicas em sua forma mais abstrata. $\mathrm{O}$ verdadeiro interesse não é a filosofia do direito, mas a lógica. $O$ trabalho filosófico não consiste em que o pensamento se concretize nas determinações (Bestimmungen) políticas, mas em que as determinações políticas existentes se volatilizem no pensamento abstrato. O momento filosófico não é a lógica da coisa, mas a coisa da lógica. A lógica não serve à demonstração do Estado, mas o Estado serve à demonstração da lógica" (MARX, 2010a, p. 38-39).

\begin{tabular}{|c|c|c|c|c|}
\hline Rovista Dialectus & Ano 5 & n. 12 & Janeiro - Julho 201 & p. $303-313$ \\
\hline
\end{tabular}


explicativa (ontoepistemológica) do real. Contudo, o que a Crítica... de Marx começa a revelar é a intrínseca relação entre o material e o ideial $^{13}$. Assim, crítica à filosofia hegeliana do direito é portadora das primeiras percepções marxianas de que a constituição do real nasce do movimento dialético do Material.

A dialética de Marx é a dialeticidade do "Material". Esta "dialeticidade" não extingue a atividade das ideias na conformação da realidade; essa "atividade", porém, é condicionada. Algumas dessas condições estão expostas na Introdução à Crítica da Filosofia do Direito de Hegel, onde Marx (2010, p. 152) assinala que "a teoria só é efetivada num povo na medida em que é a efetivação das necessidades desse povo". Todavia, essas "necessidades" não serão satisfeitas, e nem haverá transformações no mundo dos homens, se "a vida prática é desprovida de espírito" e "a vida espiritual é desprovida de prática" (MARX, 2010, p. 155). Noutro ponto, Marx (2010, p. 151) afirma que "o poder material tem de ser derrubado pelo poder material, mas a teoria converte-se em força material quando penetra nas massas". Nesses termos, Marx indica a cumplicidade entre o material e o ideial.

Outro aspecto é que a "dialeticidade do Material" não aborta a condição das contradições de serem, também, compartes do movimento de determinação do real. Se a "contradição do fenômeno" não é obra exclusiva da "Ideia", tampouco o é da "matéria natural", física, como pensam os materialistas-não-dialéticos. A razão ou causa da contradição reside no interior: na "essência" (MARX, 2010, p. 107). A contradição é conteúdo do Ser; ela não é uma substância externa a enfrentar a essência de outro Ser. A luta dos contrários travase dentro do Ser, porque é lá que mora a contradição. "Les extrêmes se touchent [...] [porque] são determinações (Bestimmungen) opostas de uma [só] essência” (MARX, 2010, p. 105).

A “dialeticidade do Material", necessariamente, não pode ser a afirmação de processos mecanicistas. Ao atacar a relação Monarca versus demais membros do Estado, apregoada por Hegel, Marx garante que tais “membros só podem se conservar reciprocamente [na síntese dialética] se o organismo inteiro é fluido [dialético] e se cada um de seus membros é superado nesta fluidez [dialeticidade] e que nenhum seja, portanto, 'imutável' e ‘inalterável'” (MARX, 2010, p. 57). Em suma: o conjunto das críticas de Marx ao idealismo hegeliano mostra que a perspectiva ontoepistemológica Material-dialética, que Marx começa

13 "Ideal" é aquilo o que decorre ou é relativo às ideias. Adotei esse neologismo após escutar o Professor Doutor José Barata-Moura, no período em que frequentei suas aulas na disciplina "Tópicos de Filosofia do Espaço Público II: Marx: dialética e materialismo", durante o meu Doutorado Sanduiche, na Universidade de Lisboa, Portugal, de janeiro a outubro de 2014.

\begin{tabular}{|l|l|l|l|l|}
\hline Q Povista Dialectus & Ano 5 & n. 12 & Janeiro - Julho 2018 & p. 303-313 \\
\hline
\end{tabular}


a construir, leva em conta o papel das "ideias", das "teorias", das "contradicções" etc. Enfim: admite a dialeticidade do Material na determinação (formação) da realidade em geral.

Marx aproxima-se de Hegel ao aceitar que o real não é um fixo, mas é o movimento $^{14}$ dialético interno ao real (aos objetos, às relações, práticas). $\mathrm{O}$ acionamento do movimento dialético é obra das contradições que, por isto, são genitoras das condições e/ou circunstâncias da realidade. Por outro lado, Marx se distancia de Hegel ao definir, como princípio da sua perspectiva filosófica, que são as condições materiais, que são dialéticas ${ }^{15}$, as fontes formativas do real.

Essa divergência de princípio, de cunho ôntico, impacta no plano epistêmico. Em razão do princípio ontológico escolhido, que afirma "o Material” como determinante do real — sem negar, com isto, o valor e a participação do pensar, das ideias, das contradições etc., na formação da realidade —, Marx é induzido a propor a dialeticidade do Material como perspectiva teórico-metodológica de análise da realidade. E, obviamente, se o real é materialdialeticamente constituído, então, ele será mais bem compreendido de uma perspectiva Material-dialética.

Cabe ressaltar que Marx, ao criticar a filosofia de Hegel, ficou ciente de que as respostas que poderiam habilitá-lo a entender e intervir nos "interesses materiais" não surgiriam somente das críticas ao Idealismo, à dialética idealista. Por essa razão, na Crítica..., Marx também ataca o velho materialismo, não dialético e antidialético ${ }^{16}$, adjetivando-o de “materialismo crasso' (krassen Materialismus), materialismo da obediência passiva, da fé na autoridade, do mecanismo de uma atividade formal, fixa, de princípios, ideias e tradições fixos" (MARX, 2010, p. 66). Este tipo de materialismo opõe-se ao Idealismo ${ }^{17}$, mas fá-lo tão-

14 "A filosofia moderna alemã que foi completada por Hegel tem como grande mérito conceber o mundo da Natureza, da História e do Espírito, como um processo, isto é, como um mundo sujeito à constante mudança, transformações e desenvolvimento contínuo, procurando também destacar a íntima conexão [lógico-dialética] que preside este processo de desenvolvimento e mudança" (ENGELS, 1979, p. 22).

15 Em carta a L. Kugelmann, Marx escreveu: “[...] meu método de desenvolvimento não é o de Hegel, uma vez que sou materialista e Hegel é idealista. A dialética de Hegel é a forma fundamental de toda a dialética, mas só depois do despojamento da sua forma mística" (MARX, 2002, p. 229).

16 Marx criticou as origens do materialismo não dialético já em sua tese de doutoramento (1939). Lá, defendeu o atomismo (materialismo) de Epicuro porque este admite o movimento, a variação, a liberdade; e atacou o materialismo de Demócrito pelo fato deste ser uma defesa do atomismo mecanicista, necessitarista. Sobre as origens, desenvolvimento e precursores do materialismo, confiram: MARX, 2003, p. 143-153.

17 No entanto, o "materialismo mecanicista" (determinista) era tão potente a ponto de atingir as ideias de Hegel. Conforme Marx, ainda que raramente, Hegel sai do Idealismo e adentra nas teias do "mais crasso materialismo". Um desses momentos é quando Hegel afirma que o rei se faz rei pelo fato de "nascer"; mas o que faz um rei, objeta Marx, é outro mecanismo de mediação, a saber: "o consentimento geral" do povo, a aceitação social do individuo como Soberano de um povo (Cf. MARX, 2010, p. 121).

\begin{tabular}{|l|l|l|l|l|}
\hline Q Rovista Dialectus & Ano 5 & n. 12 & Janeiro - Julho 2018 & p. 303-313 \\
\hline
\end{tabular}


somente para afirmar o caráter determinista das condições materiais que seriam condições derivadas da Natureza, da physis, sem conexão com o pensamento e as ideias.

Por último, uma nota breve sobre as divergências em relação à "dialética(o"). Por exemplo, semanticamente, há quem considere a palavra "dialética", que é a expressão gráfica (material) do conceito "dialética", imprópria para adjetivar, mesmo que rudemente, o substantivo "materialismo". Outros só admitem a "dialética" como sinônimo de método, e com isto indicam que a função da dialética se restringe ao campo epistemológico. Neste caso, dialética seria o nome do método que Marx seguiu na análise da realidade e na exposição dos resultados. Da nossa parte, partimos da crítica de Marx ao idealismo hegeliano para afirmar a tese de que a dialética é comparte do processo ontoepistemológico de constituição e compreensão do Material enquanto princípio determinante da realidade.

\section{REFERÊNCIAS}

BARATA-MOURA, José. Entrevista com José Batata-Moura: o material, o dialético, a ideia e a educação em Marx. Apresentação e condução da Entrevista por: Avelino Oliveira e Antonio Dias. In: Revista Cadernos de Pesquisa: Pensamento Educacional, Curitiba, vol. 9, $\mathrm{n}^{\mathbf{0}} 22$, mai./ago., p. 231-250, 2014.

DIAS, Antonio. A "educação para todos" como perspectiva de superação do capital como lógica social: análise com base no pensamento dialético de Marx. Tese de Doutorado em Educação: Filosofia da Educação, PPGE-UFPel. Pelotas, 2016, 274 f.

ENGELS, Friedrich. Anti-Düring: filosofia, economia, política, socialismo. 3 ed. Rio de Janeiro: Paz e Terra, 1979.

FLICKINGER, Hans-George. Marx e Hegel: o porão de uma filosofia social. Porto Alegre: L\&PM: CNPQ, 1986.

HEGEL, George W. F. Ciencia de la Lógica. 4 ed. Tradução Augusta Mondolfo e Rodolfo Mondolfo. Cidade do México: Edicciones Solar: Hachete, 1970.

HEGEL, George W. F. Ciência da Lógica: Excertos. Seleção e tradução: Marco A. Werle. São Paulo: Barcarolla, 2011.

LUKÁCS, György. Prolegômenos para uma ontologia do ser social: questões de princípios para uma ontologia hoje tornada possível.Tradução: Lya Luft e Rodnei Nascimento. São Paulo: Boitempo, 2010.

MARX, Karl. Crítica da Filosofia do Direito de Hegel. Tradução Rubens Enderle e Leonardo de Deus. 2 ed. rev. São Paulo: Boitempo, 2010.

\begin{tabular}{|c|c|c|c|c|}
\hline Q Rovista Dialectus & Ano 5 & n. 12 & Janeiro - Julho 2018 & p. $303-313$ \\
\hline
\end{tabular}


MARX, Karl. Carta a Ludwig Kugelmann (06/03/1868). In: MARX, Karl. O 18 Brumário e cartas a Kugelmann. 7. ed. Rio de Janeiro: Paz e Terra, 2002.

MARX, Karl. A Sagrada família. Tradução Marcelo Backes. São Paulo: Boitempo, 2003.

MARX, Karl. Posfácio à segunda edição. In: MARX, Karl. O Capital: crítica da economia política (Livro primeiro: O processo de produção do Capital, tomo I). Tradução José BarataMoura et. al. Lisboa: Edições Avante: Moscou: Progresso Editorial, 1990.

MARX, Karl. In: Einleitung [zu den "Grundrissen der Kritik der politischen Ökonomie"]. In: MARX, Karl; ENGELS, Friedrich. Marx und Engels Werke (MEW, band 42). Berlin: Dietz Verlag, 1983.

MARX, Karl. Para a Crítica da Economia Política - Prefácio. In: MARX, Karl; ENGELS, Friedrich. Obras escolhidas: em três tomos (v. 1). Tradução: Álvaro Pina. Lisboa: Edições Avante: Moscou: Edições Progresso, 1982.

MARX, Karl. Carta a Friedrick Engels (16/01/1858). In: MARX, Karl; ENGELS, Friedrick. Correspondencia. Buenos Aires: Editorial Cartago, 1973.

\begin{tabular}{|c|c|c|c|c|}
\hline Rovista Dialeatus & Ano 5 & n. 12 & Janeiro - Julho 2018 & p. $303-313$ \\
\hline
\end{tabular}

